\title{
Jiangsu province Youth Physique Health Promotion Policy Research
}

\author{
Yue Li \\ Changzhou Vocational Institute Of Mechatronic Technology, Changzhou, 213000,China
}

\begin{abstract}
Keywords: Physical health; Health promotion policies; teenagers
Abstract. By the method of documentation, questionnaire and on-the-spot investigation and other research methods, combing jiangsu youth sports health promotion policy evolution process of the relevant documents, and the implementation of related policies and also discussing influence factors. The results show that the jiangsu province youth physique health promotion policies: health promotion policy goal is too much, targeted deviation; Enforcing the policy laws and regulations is not in place; Policy evaluation lack of strict monitoring. Suggestion: keep the family, society and school three linkage mechanism, the government must be strictly implemented policy documents; Establish and improve the policies and regulations, strengthen policy evaluation.
\end{abstract}

\section{Introduction}

This study by nearly 40 years of youth sports in jiangsu province health promotion of the relevant policy documents as the research object. Through the literature material law, questionnaire investigation, expert interview and on-the-spot investigation, comb in youth sports health promotion policies and regulations related documents in jiangsu province, studies the process of the evolution of the policy, policy implementation and influence factors. Among them, according to the research aim and research content need, carries on the questionnaire design, to ensure the objective authenticity and validity of the questionnaire, the expert evaluation method is adopted for content validity and structure validity of the questionnaire, the results show that the questionnaire has high validity and reliability.

\section{The physical health of teenagers in China to promote the last 40 years relevant policy evolution process}

In March 1990, the school sports work regulations put forward the weekly schedule above 3 times of extracurricular sports activities and ensure that there is 1 hours of physical activity at a time, in August 1995, "the sports law of the People's Republic of China" from the national level of adolescent children's sports activities put forward the special security, improve the physical and mental health of youngsters' and children's; Since 2000, our country from the national related policy document or made the positive exploration in school sports; In 2001, the eighth national sports curriculum reform put forward the adhere to the "health first" guiding ideology, from the level of school physical education comprehensively promote the development of health promotion; In 2005, the ministry of health issued the "national health education and health promotion program (2005-2010)," clearly put forward the set up and improve the health education to adapt to the social development and the health promotion system; In 2007, "the country hundreds of millions of young students sunshine sports movement started, at the same time, also put forward the concrete implementation plan, namely the physical health of students in jiangsu province to promote ordinance in 2009; In 2010, our country "youth sports" twelfth five-year "plan" startup and implementation; In 2012, the development of the "China youth sports the revitalization of planning" and start; In 2012 in jiangsu province issued "students constitutional health promotion action plan; That same year, form a complete set of jiangsu province and issued "health promoting school evaluation standard of jiangsu province", strengthen the school sports education, physical education in schools will improve the youth sports accomplishment and develop healthy behavior as an important content of school education, to ensure that the students in the school sports and exercise time; In 2014 the state council "about speed up the development of sports industry, promote the sports consumption of the several opinions about the 
youth sports work requirements and other documents and conference spirit to further strengthen the regulations and policies of the Chinese youth sports foundation construction and the top design, from the national level to promote the healthy development of our country teenagers; 2014 national student physical health standard (revised in 2014), in April 2016, the state council general office after the eighth national sports curriculum reform is further introduced "about strengthening school sports promote students" physical and mental health of comprehensive development, thus the party central committee and state council attaches great importance to the school sports, at the same time, the third plenary session of the 18 made to strengthen the importance of physical education and extra-curricular exercise deployment, in addition to strengthen the school sports under the state council put forward clear requirements.

\section{Youth physique health promotion policy implementation present situation analysis of jiangsu province}

Policy implementation process perfecting relevant supporting measures and the concrete implementation plan. Survey found that policy of jiangsu province in perfecting relevant supporting measures and the concrete implementation plan. In order to better cooperate with the education department to carry out "sunshine sports" millions of students, in jiangsu province in the implementation of relevant national youth sports policy or file at the same time, according to the regional characteristics of jiangsu province, the 13 the market one by one to promote youth sunshine sports league.

In order to further implement the state council on strengthening the central committee of the communist party of China youth sports to enhance teenagers' opinions ", in jiangsu province has launched the physical health of students in jiangsu province to promote ordinance and the student physique health promotion action plan, we will accelerate the establishment of a physical health of students management system and early warning mechanism, the implementation of student physique health promotion action plan. In addition, in December of 2010, established the physical health of students in jiangsu province to promote jiangsu province department of education research center. Its task is to undertake the monitoring and scientific research work in the physical health of students in jiangsu province, to carry out the physical health of students to promote academic research, the department provides policy Suggestions and advice for the government. [1]

Jiangsu juvenile physical health promotion of the policy implementation process of the allocation of resources. The number of primary and secondary school physical education teachers configuration. The national school sports pilot basic sanitation standard "regulation: the school shall, within the faculty of approved in total BianZhiShu according to the characteristics of the physical education teaching, according to the teaching plan in physical education teaching hours and the need of extracurricular sports activities, physical education teachers. According to the survey basically accord with a country school physical education in the areas of southern pilot basic sanitation standard, the reason is the school and the family attaches great importance to physical training and extracurricular sports activities, led to the demand of school physical education teachers, and some counties and cities in the south of jiangsu regional economic development better, teachers' salary is higher, it is easy to attract the teacher. Because of north jiangsu and middle region's economic development is relatively backward, the survey found that on the one hand, college graduates don't want to in the past, have a high level of physical education teachers move led to the lack of PE teachers, a lot of physical education, the set - free - set - this class model class.

Fields and sports equipment allocation of resources. Site resources is to develop school sports activities and sports teaching basic guarantee, through the investigation of jiangsu number of sports facilities can satisfy the basic teaching of primary and secondary schools. $19.2 \%$ of teachers think site resources is very abundant, $26.9 \%$ school think that space is enough, $38.5 \%$ of basic school field meet the routine teaching, $15.4 \%$ think that cannot satisfy the development of classroom teaching. Good sports equipment is to ensure that the basic condition of sports class normal, the survey found that primary and middle schools in sunan region equipment is very abundant, and updated every year in a 
planned way. Because of the economic level is relatively low in north jiangsu, $73 \%$ of school physical education teachers think can not satisfy the sports teaching very well, led to a certain technology is difficult to carry out teaching, tend to form the "empty" and simple in hand imitate the status of the practice.

Health education resources. Health education of primary and secondary schools in jiangsu province and big recess sports activities, the investigation of the whole school are opened a health education class, and $97 \%$ of the school each semester to open more than seven hours, $48 \%$ of the amount of school health education classes to 10 hours, only $3 \%$ of the schools have no full class. Health education contents mainly relates to the safety and health, correct students' incorrect reading and writing posture, close your eye time, health behavior and health habits, disease prevention, drug anti-smoking anti-alcohol and health knowledge such as science and nutrition. These reflect the student physique health promotion ordinance issued in jiangsu province after schools perform effect is better.

A greater difference between urban and rural student physique test hardware conditions, physical test numerical obvious error. Primary and secondary schools in jiangsu province fitness testing content and execute standard is according to the national student physical health standard, the test content one to two years included body mass index (BMI), 50 meters, vital capacity in succession, crook proneness, 6 items such as 1 minute skip rope; Three - four grade increases 1 minute sit-ups and so on seven; On the basis of the fourth grade five, six grade increased by 50 meters $8 \times 8$ running back and forth, etc; Junior high school above included body mass index, vital capacity, 50 meters in succession, crook proneness, standing long jump, pull-ups (male)/minute sit-ups (female) and 1000 meter run (male) / 800 - meter run (female), etc. 8. According to the survey, each school can seriously to complete, according to the requirements of national physical fitness test conducted once a year the cervix and submitted to the cervix figures carefully. $37 \%$ of schools reported data fraud case, $25 \%$ of schools are hiring part-time cervix teacher to assist the work, and school because of a shortage of cervix equipment and personnel, height and weight for both direct data reported by the students, lead to obvious physical test data error phenomenon.

\section{Jiangsu youth physique health promotion policy problems that exist in the implementation process}

Health promotion policy goal is too much, targeted have deviation. Known as "the country hundreds of millions of young students sunshine sports", only the action plan put forward the slogan of "exercise an hour every day". As for what kind of group, but there was no clear requirement. Obese adolescents exercise an hour can achieve movement effect, how to control the intensity; Low vision students whether can through exercise for an hour can reduce status and other issues. Moreover, the student physique health promotion ordinance in jiangsu province is the first dedicated to promoting students physical health local rules and regulations. Only from sports, health, nutrition, security supervision and legal responsibility and so on request. The regulation to strengthen the students' promote the healthy growth of students is of great significance to some extent, but for the implementation of the policy is very difficult to operate, pertinence and operability is questionable.

Policy law enforcement does not reach the designated position. Since reform and opening-up of our country in order to speed up the sports legal system construction, to strengthen the youth physique health promotion work, also enacted various laws and regulations, but in these laws and regulations still exist in the macroscopic regulation, less specific implementation measures, more supervision and punishment is not in place, up to have difficulty operation and so on, makes it hard for promulgated laws and regulations to implement. [2], for example, in jiangsu province in violation of regulations on the physical health of students in jiangsu province to promote the relevant terms and failed to correct the school, the relevant legal liability shall be investigated in accordance with the provisions. The "relevant" express very fuzzy legal responsibility. At present, our country school sports work to promote the physical health of teenagers play a key role, however, school sports security is currently the main factors of restricting students sports, security problem solving is not 
good, which are tied, the vigor of school sports head - hard. The task of health promotion, how to do? Is worth thinking about.

Policy evaluation lack of strict monitoring. Policy evaluation is validity for policy implementation and policy target group is to achieve the desired effect, according to certain standards and procedures, inspection in the process of policy implementation stages, each link of the detection, evaluation and feedback process of judgment. To judge whether the related policy science, could prove crucial to achieve the desired effect. Youth sports activities throughout the jiangsu province, however, the system is had, implement when it be discounted. Teacher shortage of teachers, insufficient resources, physical test data to lie about the phenomenon still exists.

\section{Countermeasures and Suggestions}

Keep the family, society and school three linkage mechanism, the government must be strictly implemented the policy document. Jiangsu province can be tempted by "family, society and schools" tripartite linkage mechanism, the measures of sports and exercise program, to create students fitness comprehensive evaluation method, the students in the school sports activities will also be included in the evaluation, let the family to help children maintain a healthy body, play an active role. Via such a measure aimed at encouraging students comprehensive look at sports, and have fun from movement, continue to remain active after school. In addition, the company by buying tongfang health provided by third party service, students' physical health test system, schools and government all equipment and supporting services are provided by tongfang health company, fully guarantee the reliable data, both at the same time greatly reduce the burden of the education department [3]. A sound system of students physical exercise, the school will give students in the school extracurricular sports activities in teaching plan, included in the work and rest time arrangement, and physical education teaching content cohesion, to ensure that students an hour each day to campus sports activities [4]. Schools from kindergarten should start to arrange a compulsory sports, like swimming, football, gymnastics, track and field.

Establish and improve the policies and regulations, strengthen policy evaluation. Revise and improve the present sports laws and regulations in the refinement of not clear words. In order to solve the current school sports security restriction sports resistance, first of all, the school shall do all safe hidden trouble, do nip in the bud, government departments should be legal. In addition, the pilot can encourage local governments promote student sports safety accident third-party mediation method [5]. Solve the contradiction between the parents and the school, minus the PE teachers' psychological obstacles, to ensure the quality of the sports classroom, To improve physical health level of teenagers.

\section{Funds project:}

Jiangsu province education science the Twelfth Five-yearproject (No. :T - c / 2015/018)

\section{References}

[1] introduction to physical health of students in jiangsu province to promote research center [EB/OL]. http://sh.njnu.edu.cn/cn/About-tzzx

[2] liu, liu, etc. Between the child and adolescent health regulations and policies for health promotion research [J] Shanghai education scientific research, preceding 2015.08

[3] high-tech equipment + third-party service Beijing elementary student physical health test even tenabled into theera of Internet

[EB/OL].http://www.jyb.cn/basc/xw/201510/t20151026_640946.html

[4] nine departments such as the ministry of education on further promoting the development of the community education 
[EB/OL]. HTTP: / / http://www.goschool.org.cn/xw/zcwj/2016-07-20/9086.html

[5] of the state council general office on strengthening school sports to promote the development of students physical and mental health comprehensive opinions

[EB/OL]. http://www.sport.gov.cn/n10503/c723294/content.html 